\title{
Bitki Yüzey Artığı Kaplama Yüzdesinin Belirlenmesinde Kullanılan Farklı Yöntemlerin Karşılaştırılması
}

\author{
İlknur DURSUN, Ergin DURSUN*, Abdullah BEYAZ \\ Ankara Üniversitesi, Ziraat Fakültesi, Tarım Makinaları ve Teknolojileri Mühendisliği Bölümü, Ankara, Türkiye \\ *e-posta: edursun@agri.ankara.edu.tr
}

\begin{abstract}
Özet: $\mathrm{Bu}$ araştırmanın amacı; buğdayın yüzey artıklarıyla kaplı tarla koşulunda cetvel yöntemi, kesişen hat yöntemi, ImageJ görüntü işleme programı ve Labview Vision Assistant Modülüyle yüzey artığı kaplama yüzdesinin belirlenmesi ve elde edilen sonuçların karşılaştırılmasıdır. ImageJ görüntü işleme programı ve Labview Vision Assistant Modülüyle yüzey artığı kaplama yüzdesinin belirlenmesi için, buğday yüzey artıklarıyla kaplı bir tarlanın çeşitli yerlerinden akıllı cep telefonunun dijital kamerasıyla fotoğraflar çekilmiştir. Araştırma sonunda; cetvel, kesişen hat, ImageJ görüntü işleme programı ve Labview Vision Assistant Modülü kullanılarak ortalama bitki yüzey artığ kaplama yüzdeleri sırasıyla \% 44.13, \% 50.72, \% 56.56 ve \% 64.49 olarak belirlenmiştir. Yapılan varyans analizi; kesişen hat ve ImageJ görüntü işleme yöntemlerinden bulunan sonuçlar arasındaki farklılığın istatistiksel olarak önemsiz, bu yöntemlerle diğer yöntemlerden elde edilen sonuçlar arasındaki farklılıkların ise önemli olduğunu göstermiştir.
\end{abstract}

Anahtar kelimeler: Bitki yüzey artığı kaplama yüzdesi, Cetvel yöntemi, Görüntü işleme yöntemi, ImageJ, kesişen hat yöntemi, Labview

\section{Comparison of Different Methods Used For Determination of Percent Crop Residue Cover}

\begin{abstract}
The purpose of this research was to determine the percent crop residue cover using meter stick method, line transect method, image processing software ImageJ and Labview Vision Assistant Module in the field condition covered with wheat surface residues and to compare results obtained from these measuring methods. In order to determine the percent crop residue cover using ImageJ image processing software and Labview Vision Assistant Module, photographs were taken with a digital camera of the intelligent mobile phone from various places of a field covered with wheat surface residues. At the end of study, the mean percent crop residue cover using meter stick method, line transect method, image processing software ImageJ and Labview Vision Assistant Module were determined as 44.13\%, 50.72\%, 56.56\% and 64.49\%, respectively. Variance analysis showed that the difference between the results obtained from the line transect method and ImageJ is statistically insignificant while the differences between the results obtained from these methods and the other methods are significant.
\end{abstract}

Key words: Percent crop residue cover, Meter stick method, Image processing method, ImageJ, Line transect method, Labview

\section{Giriş}

Toprak yüzeyinde kalan bitki yüzey artıklarının su ve rüzgar erozyonunun önlenmesi, nem kaybının azaltılması, yabancı otların kontrol edilmesi, toprak strüktürünün iyileştirilmesi, organik madde içeriğinin artırılması, yüzey akışlarının azaltılması, toprak su geçirgenliğinin artırılması, kaymak tabakasının önlenmesi ve toprak sıcaklığının artırılması gibi birçok yararı vardır (Dickey ve ark. 1981; Dickey ve ark. 1986; Wysocki 1988; Aase ve Tanaka 1991; Daughtry ve ark. 1997; Rice 2002; Bannari ve ark. 2006; Al-Kaisi ve Hanna 2009; Anonim 2015; Dursun 2015; Anonim 2016a). Bu nedenle bitki yüzey artığı planlamasının yapılması oldukça önemli olup, planlamanın yapılabilmesi için kaplama yüzdesinin belirlenmesi gerekir.

Bitki yüzey artığı kaplama yüzdesi; toprak işleme, ekim, gübreleme, hasat-harman gibi bitkisel üretim aşamalarından sonra toprak yüzeyinde kalan anız, sap, saman gibi bitkisel artıkların toprak yüzeyini kaplama yüzdesi olarak tanımlanır. Bitki yüzey artığı kaplama yüzdesinin belirlenmesinde fotoğraf karşılaştırma, cetvel, kesişen hat, ot sayımı, hesaplama, lazerli tarayıcıyla ölçüm, mavi 1şıklı floresan lambayla görüntüleme, spektral yansımayla ölçüm, uzaktan algılama ve görüntü işlemeyle analiz gibi çeşitli yöntemlerden yararlanılır (Laflen 
ve ark. 1981; Dickey ve Havlin 1985; Hickman ve Schoenberger 1989; Corak ve ark. 1993; McMurtrey ve ark. 1993; Shelton ve ark. 1995; Daughtry ve ark. 1997; Dursun 2002; Streck ve ark. 2002; Presley 2013; Karabacak 2007; Al-Kaisi ve Hanna 2009; Zheng ve ark. 2014; Anonim 2015). Bu yöntemlerden bazıları gözlem ve tahmin esaslı basit, bazıları ise kısa sürede ve güvenilir olarak tarla koşullarında ölçüm yapılmasına yarayan modern yöntemlerdir (Daughtry 2001; Dursun 2002; Daughtry ve ark. 2006).

Buğday, mısır, ayçiçeği, soya, kanola, bezelye vb. yüzey artıklarıyla kaplı tarla koşullarında görüntü işleme yöntemiyle bitki yüzey artığı kaplama yüzdesinin belirlenmesi konusunda çeşitli çalışmalar yapılmıştır (Meyer ve ark. 1988; Morrison ve Chichester 1991; Corak ve ark. 1993; Daughtry ve ark. 1997; Streck ve ark. 2002; Bannari ve ark. 2006; Karabacak 2007). Bu araştırmalarda, tarla yüzeyinin siyah-beyaz ya da renkli fotoğraflarının elde edilmesinde digital kamera, video ya da uydu görüntülerinden yararlanılmıştır. Tarla yüzeyinin fotoğrafları, JPEG veya RGB gibi formatlarda bilgisayara aktarılmış ve çeşitli görüntü işleme programlarıyla analiz edilmiştir. Görüntü işleme ve kıyas yöntemi ile bulunan bitki yüzey artığı kaplama yüzdeleri arasındaki ilişkilere ait korelasyon katsayıları değerleri; Meyer ve ark. (1988) tarafından soya ve misırda 0.96-0.98, Morrison ve Chichester (1991) tarafindan 0.99 ve Karabacak (2007) tarafindan ise buğdayda 0.91, misırda 0.70, ayçiçeğinde 0.67 olarak bildirilmiştir. Anonim (2016b) tarafından, bitki yüzey artığı kaplama yüzdesinin ölçülmesine yarayan, Android tabletlere uygun bir yazılım geliştirildiği belirtilmiştir. Programın çalışma ilkesinin, ölçüm yapılacak olan tarlanın görüntüsünün çekilerek programa yüklenmesi, bitki yüzey artığı ve toprak renklerinin seçilmesi, arka planın şeffaf hale getirilmesi, görüntü renginin ayarlanması ve tabletin ekranında bitki yüzey artığı kaplama yüzdesinin gösterilmesi olarak açıklanmıştır.

Bitki yüzey artığı kaplama yüzdesinin tahmin edilmesine ya da doğrudan tarladan ölçülmesine yarayan ölçüm yöntemleri arasında bitki yüzey artığı kaplama yüzdesini kısa sürede ve doğru olarak belirleyecek uygun yöntemin seçilmesi oldukça önemlidir. Çünkü toprak ve suyu korumaya yönelik toprak işleme tekniklerinde, toprak işlemenin planlanması ya da toprak işleme ekipmanlarının seçiminde temel kriterlerden birisi, bitki yüzey artığı kaplama yüzdesidir. Toprak işleme ve ekimden sonra toprak yüzeyinde kalması istenen bitki yüzey artığı kaplama yüzdesine göre toprak işleme alet makinalarının seçilmesinin toprak erozyonunun ve nem kaybının azalması, toprak sıkışmasına yol açılmaması, topraktan atmosfere $\mathrm{CO}_{2}$ salınımının önlenmesi gibi birçok yararı vardir.

Bu araştırmada; buğdayın yüzey artıklarıyla kaplı tarla koşulunda cetvel yöntemi, kesişen hat yöntemi, ImageJ görüntü işleme programı ve Labview Vision Assistant Modülüyle bitki yüzey artığı kaplama yüzdesinin belirlenmesi ve elde edilen sonuçların karşılaştırılması amaçlanmıştır.

\section{Materyal ve Metot}

Araştırmada, deneme alanı olarak hasat edilmiş ve hiçbir toprak işleme yapılmamış olan buğdayın yüzey artıklarıyla kaplı bir tarla koşulu seçilmiştir. Tarla toprağı, hafif toprak bünyesindedir. Bitki yüzey artıklarını, biçme yüksekliğinin altında kalan toprak yüzeyindeki saplar ile toprak yüzeyine serbestçe yayılmış haldeki saplar oluşturmaktadır.

Tarlada örnekleme yapılacak alanların sınırlarının belirli olması amacıyla ahşap çıtalardan yapılmış ve boyutları 30x30 cm olan bir örnek alma çerçevesinden yararlanılmıştır (Al-Kaisi ve Hanna 2009; Anonim 2015). Shelton ve Jasa (1995) tarafından da belirtildiği şekilde örnek alma çerçevesinin tarlanın sel, kuraklık, toprak sıkışması, böcek ve yabancı ot zararına uğramış vb. kısımlarına yerleştirilmemesine dikkat edilmiştir. Örnek alma çerçevesiyle belirlenen alanların fotoğrafları, Samsung Galaxy S7 marka ve modeldeki akıllı cep telefonunun 12 megapiksel çözünürlükteki dijital kamerasıyla çekilmiştir. Fotoğraf çekimleri sırasında akıllı cep telefonunun kamerası, tarla yüzeyine aşağıya doğru dik konumda ve çekim yüksekliği sabit olacak şekilde tutulmuştur. Çekilen dijital fotoğraflar, bilgisayara aktarılarak JPEG formatına dönüştürülmüştür. Araştırmada; bitki yüzey artığı kaplama yüzdesinin belirlenmesinde cetvel yöntemi, kesişen hat yöntemi, ImageJ görüntü işleme programı ve Labview Vision Assistant Modülü olmak üzere 4 farklı yöntemden yararlanılmıştır.

Cetvel ve kesişen hat yöntemleri, esas olarak birbirine benzeyen ve doğrudan tarladan ölçüm yapılmasına yarayan basit yöntemlerdir. Her iki yöntem, tarla yüzeyine yerleştirilen şerit metrenin kenarındaki bölüntülerden bitki yüzey artıklarıyla kesişenlerin sayısının toplam bölüntü sayısına oranlanması ilkesine dayanır. Cetvel ve kesişen hat yöntemleri arasındaki en önemli fark, cetvel yönteminde cetvelin ya da şerit metrenin önceki bitki sıralarına dik konumda olacak şekilde, kesişen hat yönteminde ise $45^{\circ}$ ' lik açı yapacak şekilde çapraz olarak yerleştirilmesidir (Şekil 1), (Dickey ve ark. 1986; Shelton ve Jasa 2009). Şerit metrenin kenarındaki her cm bölüntüsünden bitki yüzey artıklarıyla kesişenler sayılmıştır. Bitki yüzey artığı kaplama yüzdesi, kesişen bölüntü 
sayısının toplam bölüntü sayısına oranlanması ve bulunan değerin 100 ile çarpılmasıyla hesaplanmıştır (Laflen ve ark. 1981; Al-Kaisi ve Hanna 2009; Anonim 2015).
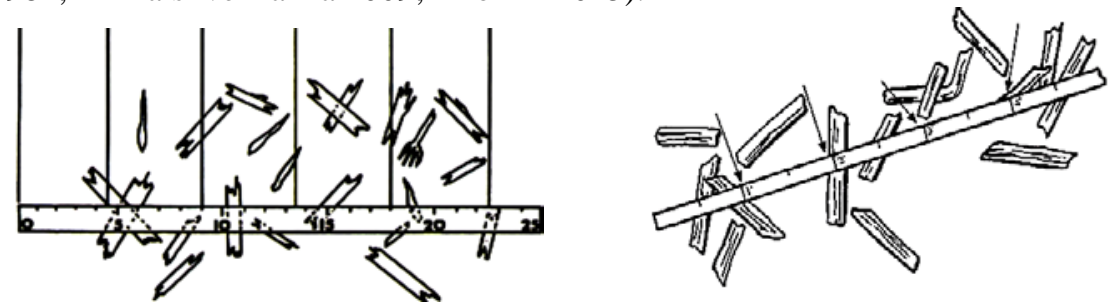

Şekil 1. Cetvel ve kesişen hat yöntemleri (Shelton ve Jasa 2009; Anonim 2015).

Araştırmada kullanılan yöntemlerden birisi olan görüntü işlemede, ilk olarak ImageJ versiyon 1.50b görüntü işleme programı kullanılmıştır. Bu program, bilimsel olarak çok boyutlu ve geniş skaladaki görüntülerin işlenmesinde yararlanılan açık kaynaklı bir programdır. Java 1.8.0_60 (64 bit) kodlamasını kullanmaktadır. ImageJ görüntü işleme programına aktarılan JPEG formatındaki digital fotoğraflar, öncelikle 8 bit-gri renk formatına dönüştürülmüş ve daha sonra renk eşik değerinin belirlenmesi amacıyla program ara yüzündeki Process menüsünden Threshold butonuyla işlenmeye hazır hale getirilmiştir. Bu sayede, toprak ve bitki yüzey artıklarının birbirlerinden ayrılmaları sağlanmıştır. Son olarak, Analyze menüsünden Histogram seçeneği kullanılarak List komutu verilmiştir (Şekil 2). Bunun sonucunda, siyah ve beyaz renklerdeki piksel sayılarına bağlı olarak bitki yüzey artığı kaplama yüzdeleri, bilgisayar ekranında çizelge halinde elde edilmiştir.

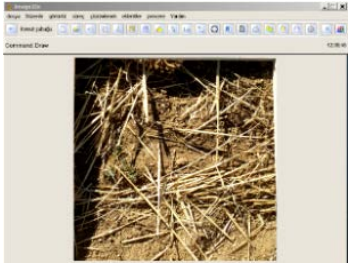

(a)

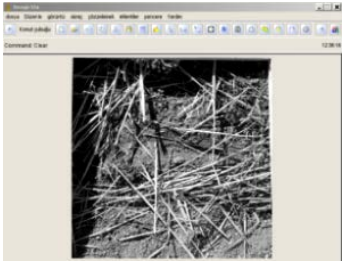

(b)

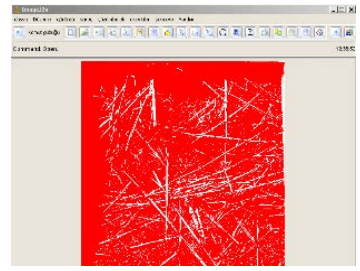

(c)

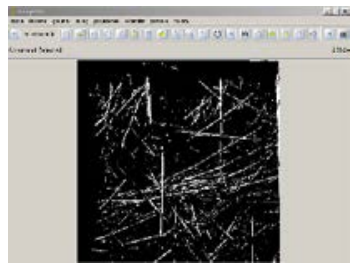

(d)

Şekil 2. ImageJ görüntü işleme programına aktarılan JPEG formatındaki dijital fotoğraf (a), fotoğrafın 8 bit-gri renge dönüştürülmesi (b), renk eşik değerinin belirlenmesi (c) ve Threshold işleminin yapılması (d).

Araştırmada, bitki yüzey artığı kaplama yüzdesinin belirlenmesinde kullanılan bir diğer görüntü işleme yöntemi ise Labview platformu üzerinde dahili olarak bulunan Labview Vision Asistant Modülüyle ölçümdür. Labview sözcüğü, "Laboratory Virtual Instrument Engineering Workbench" kelimesinin ilk harflerinden oluşan bir kısaltmadır. Görüntü işleme, otomasyon, enerji analizi, robotik, otomotiv, tıp, gıda, kimya, jeoloji, istatistik, matematik gibi çeşitli bilim dallarında kullanılan grafiksel programlama dili arabirimidir (Anonim 2016). Test, ölçüm, veri oluşturma, işleme ve izleme gibi amaçlarla kullanılır. Algoritma geliştirilmesine yarayan görsel bir platformdur. Grafik ve ekran çıkışlarının izlenebildiği karşılıklı etkileşim esasına dayanan bir ara yüz alanı vardır. Bu araştırmada, Labview grafiksel arayüzü üzerinde bir Labview modülü olan Labview Vision Assistant Modülünden yararlanılmıştır. Tarladan çekilen fotoğraflar, JPEG formatında bilgisayara kaydedilmiş ve ardından Labview programına aktarılmıştır. Daha sonra renk eşik değerinin belirlenmesi için program ara yüzündeki Color Thresold seçeneği kullanılarak, Kırmızı-Yeşil-Mavi (Red-Green-Blue) renk kanallarından mavi kanal üzerinde maksimum değeri ile oynanarak eşikleme için optimizasyon yapılmış ve toprak ile bitki yüzey artıkları birbirinden ayrılmıştır (Şekil 3 ve Şekil 4). Eşikleme sırasında temel kriter, bitki yüzey artıklarının ve toprağın gerçeğe en uygun şekilde net olarak birbirlerinden ayırt edilmesi koşulu olmuştur. Görüntü işleme fonksiyonları (Image Processing Functions) menüsünden Histogram seçeneği kullanılarak elde edilen siyah ve kırmızı renk değerlerine ait piksel sayım sonuçları, Excel'e gönder seçeneği ile alınarak veriler üzerinden değerlendirme yapılmıştır (Şekil 5). 


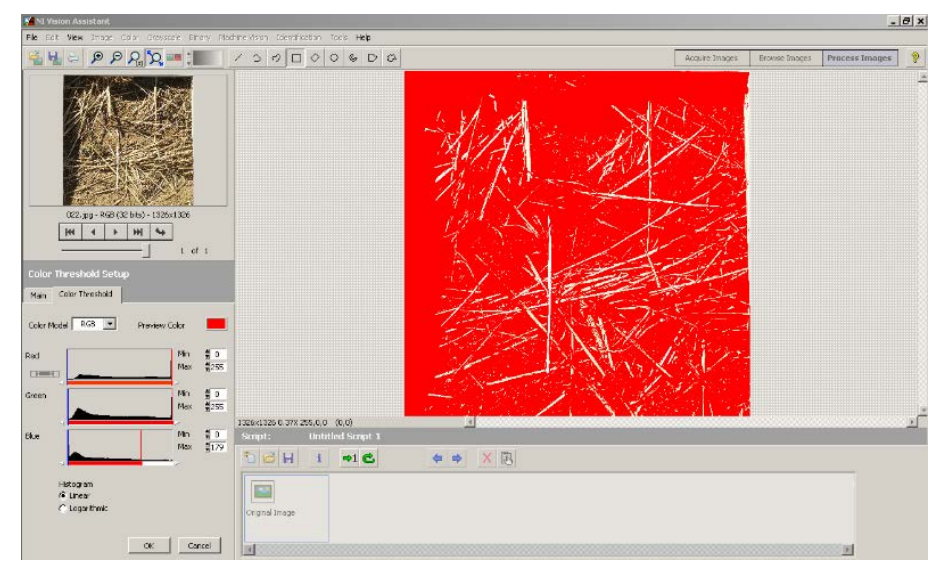

Şekil 3. Bitki yüzey artığı görüntüsü üzerinden renk eşiği (Color Threshold) değerinin optimizasyonu.

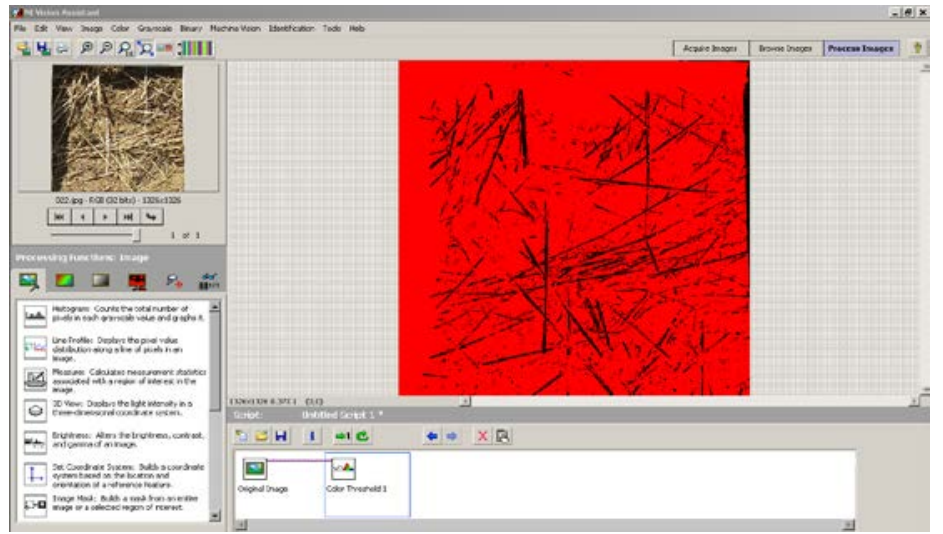

Şekil 4. Eşikleme (Color Threshold) sonrası analiz edilmeye uygun hale gelen bitki yüzey artığı görüntüsü.

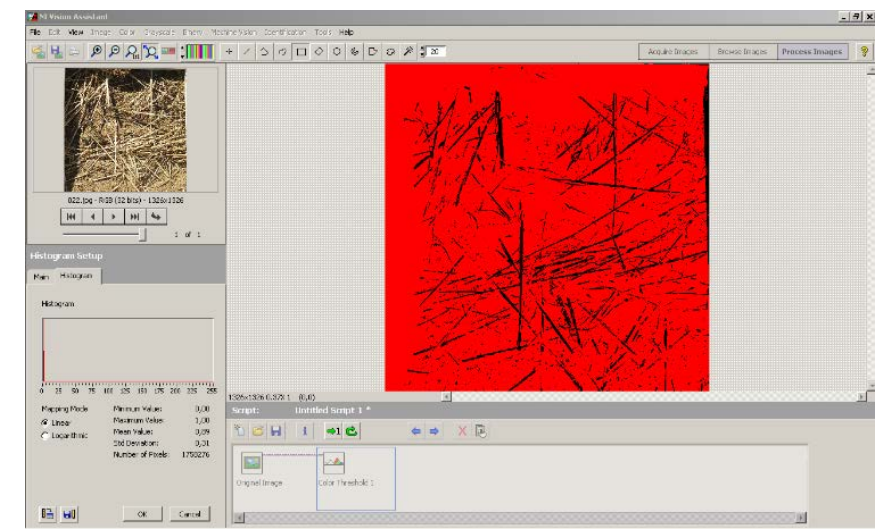

Şekil 5. Histogram analizi.

Araştırma sonucunda; cetvel yöntemi, kesişen hat yöntemi, ImageJ görüntü işleme programı ve Labview Vision Assistant Modülünden bulunan bitki yüzey artığı kaplama yüzdeleri istatistiksel analize tabi tutulmuştur. İstatistiksel analizde SPSS 20 paket programı kullanılmıştır. Araştırmadan elde edilen veriler, tekrarlanan ölçümlü varyans analizine tabi tutulmuş ve ortalamalar arasındaki farkl1lıklar Duncan çoklu karşılaştırma testi yöntemine göre test edilmiştir. Ayrıca, farklı yöntemler ile yapılan ölçümlerin benzerliği hakkında bilgi sahibi olmak için grup içi korelasyon katsayısı hesaplanmıştır. İstatistiksel analizlerde Kocabaş ve ark. (2013)' dan yararlanılmıştır.

\section{Bulgular ve Tartışma}

Yapılan hesaplamalar sonucunda cetvel yöntemi, kesişen hat yöntemi, ImageJ görüntü işleme programı ve Labview Vision Assistant Modülünden bulunan bitki yüzey artığı kaplama yüzdeleri ve ortalamaları Çizelge 1' 
de verilmiştir. Çizelge 1' den anlaşılacağı gibi, ortalama değer olarak en yüksek bitki yüzey artığı kaplama yüzdesi \%64.49 ile Labview Vision Assistant Modülünden, en düşük bitki yüzey artığı kaplama yüzdesi ise \%44.13 ile kesişen hat yönteminden elde edilmiştir. Görüntü işleme yöntemiyle (ImageJ ve Labview) bulunan ortalama bitki yüzey artığı kaplama yüzdeleri, cetvel ve kesişen hat yöntemleriyle bulunan ortalama bitki yüzey artığı kaplama yüzdelerinden daha büyüktür.

Farklı yöntemlerle elde edilen sonuçlara uygulanan tekrarlanan ölçümlü varyans analizi sonucunda, belirlenen bitki yüzey artığı kaplama yüzdeleri bakımından en az iki yöntem arasında farkın istatistik olarak önemli olduğu bulunmuştur $(\mathrm{p}<0.01)$ (Çizelge 2$)$. Yöntemler arasındaki farklılığın belirlenmesi amacıyla yapılan Duncan çoklu karşılaştırma testi sonuçları ise Çizelge 3' de verilmiştir.

Çizelge 1. Farklı yöntemlerle bulunan bitki yüzey artı̆̆ kaplama yüzdeleri

\begin{tabular}{ccccc}
\hline \multirow{2}{*}{ Örnek } & \multicolumn{3}{c}{ Bitki yüzey artığı kaplama yüzdesi (\%) } \\
\cline { 2 - 5 } & $\begin{array}{c}\text { Cetvel } \\
\text { yöntemi }\end{array}$ & $\begin{array}{c}\text { Kesişen hat } \\
\text { yöntemi }\end{array}$ & Görüntü işleme yöntemi \\
\cline { 3 - 5 } & 20.00 & 40.07 & 34.18 & LmageJ \\
\hline 1 & 16.66 & 30.65 & 45.69 & 41.75 \\
2 & 43.33 & 68.36 & 70.83 & 82.75 \\
3 & 70.00 & 50.00 & 83.84 & 89.90 \\
4 & 50.00 & 51.86 & 53.57 & 62.33 \\
5 & 45.00 & 42.43 & 52.94 & 59.56 \\
6 & 36.66 & 37.72 & 47.83 & 52.81 \\
7 & 53.33 & 58.93 & 60.35 & 75.37 \\
8 & 33.33 & 42.43 & 39.83 & 48.92 \\
9 & 56.66 & 61.29 & 73.78 & 79.91 \\
10 & 57.00 & 60.11 & 65.38 & 76.35 \\
11 & 30.00 & 40.08 & 31.87 & 50.97 \\
12 & 40.00 & 44.79 & 55.63 & 71.54 \\
13 & 70.00 & 70.72 & 74.99 & 82.32 \\
14 & 40.00 & 61.29 & 57.73 & 61.03 \\
\hline 15 & 44.13 & 50.71 & 56.56 & 64.49 \\
\hline
\end{tabular}

Çizelge 2. Farklı yöntemlerle bulunan bitki yüzey artığı kaplama yüzdelerine ilişkin varyans analizi sonuçları

\begin{tabular}{cccccc}
\hline $\begin{array}{c}\text { Varyasyon } \\
\text { kaynakları }\end{array}$ & $\begin{array}{c}\text { Serbestlik } \\
\text { derecesi }\end{array}$ & $\begin{array}{c}\text { Kareler } \\
\text { toplamı }\end{array}$ & $\begin{array}{c}\text { Kareler } \\
\text { ortalaması }\end{array}$ & F & P \\
\hline Genel & 59 & 16275.997 & - & & \\
Parseller arası & 14 & 11111.476 & - & & \\
Parseller içi & 45 & 5164.521 & - & 26.326 & $.000^{* *}$ \\
Yöntemler arası & 3 & 3371.556 & 1123.852 & & \\
Hata & 42 & 1792.965 & 42.690 & & \\
\hline \multicolumn{7}{c}{$\mathrm{P}<0.01$} & & & \\
\hline
\end{tabular}

Çizelge 3. Kullanılan yöntemlerle bulunan bitki yüzey artığı kaplama yüzdelerine ilişkin Duncan testi sonuçları

\begin{tabular}{ccccc}
\hline Yöntemler & $\mathbf{N}$ & $\overline{\mathbf{X}} \pm \mathbf{S} \overline{\mathbf{X}}$ & Minimum & Maksimum \\
\hline Cetvel yöntemi & 15 & $44.13 \pm 4.10 \mathrm{C}$ & 16.66 & 70.00 \\
Kesişen hat yöntemi & 15 & $50.72 \pm 3.13 \mathrm{~B}$ & 30.65 & 70.72 \\
ImageJ görüntü işleme programı & 15 & $56.56 \pm 3.96 \mathrm{~B}$ & 31.87 & 83.84 \\
Labview Vision Assistant Modülü & 15 & $64.49 \pm 4.38 \mathrm{~A}$ & 31.75 & 89.90 \\
\hline Aynı sütunda farklı harflerle gösterilen ortalamalar arasındaki farklılıklar istatistiksel olarak önemlidir (P $<0.01)$.
\end{tabular}

Çizelge 3.' den anlaşılacağı gibi, yalnızca kesişen hat yöntemi ve ImageJ görüntü işleme programından bulunan ortalama değerler arasındaki farklılık önemsiz, bu yöntemlerle diğer yöntemler arasındaki farklılıklar ise istatiksel olarak önemli bulunmuştur.

Farklı ölçüm yöntemleriyle elde edilen bitki yüzey artığı kaplama yüzdelerinin benzerliğini kontrol etmek için 
grup içi korelasyon katsayısı hesaplanmış ve önemlilik testi sonucunda, yöntemler arasındaki korelasyonun istatiksel olarak önemli olduğu belirlenmiştir (Grup içi korelasyon katsayısı $=0.597, \mathrm{P}<0.01$ ).

Şekil 6’ da, cetvel yöntemi ile görüntü işleme yöntemlerinden (ImageJ ve Labview), Şekil 7'de kesişen hat yöntemi ile görüntü işleme yöntemlerinden, Şekil 8' de ise hem cetvel ve kesişen hat yöntemleri ile bulunan bitki yüzey artığı kaplama yüzdeleri ve hem de görüntü işleme yöntemleri olarak kullanılan ImageJ ve Labview Vision Assistant Modülünden bulunan bitki yüzey artığı kaplama yüzdeleri arasındaki ilişkilere ait eğilim çizgileri ve Pearson korelasyon katsayıları gösterilmiştir.
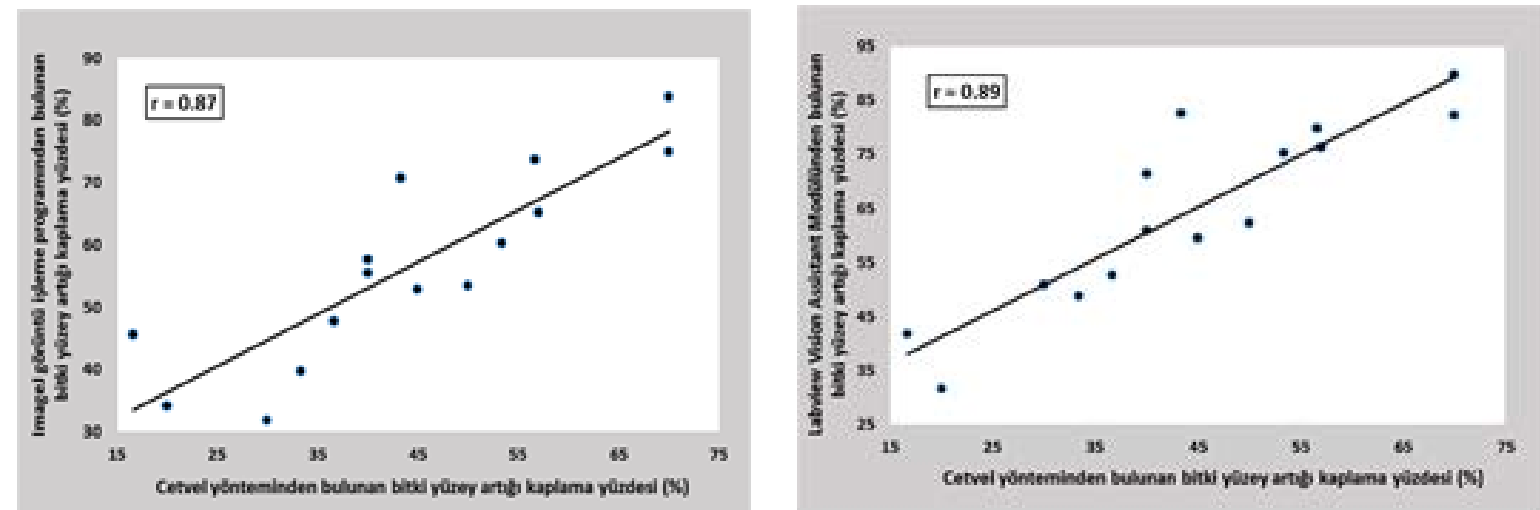

Şekil 6. Cetvel yöntemi ile görüntü işleme yöntemleri (ImageJ ve Labview) arasındaki ilişkiler.
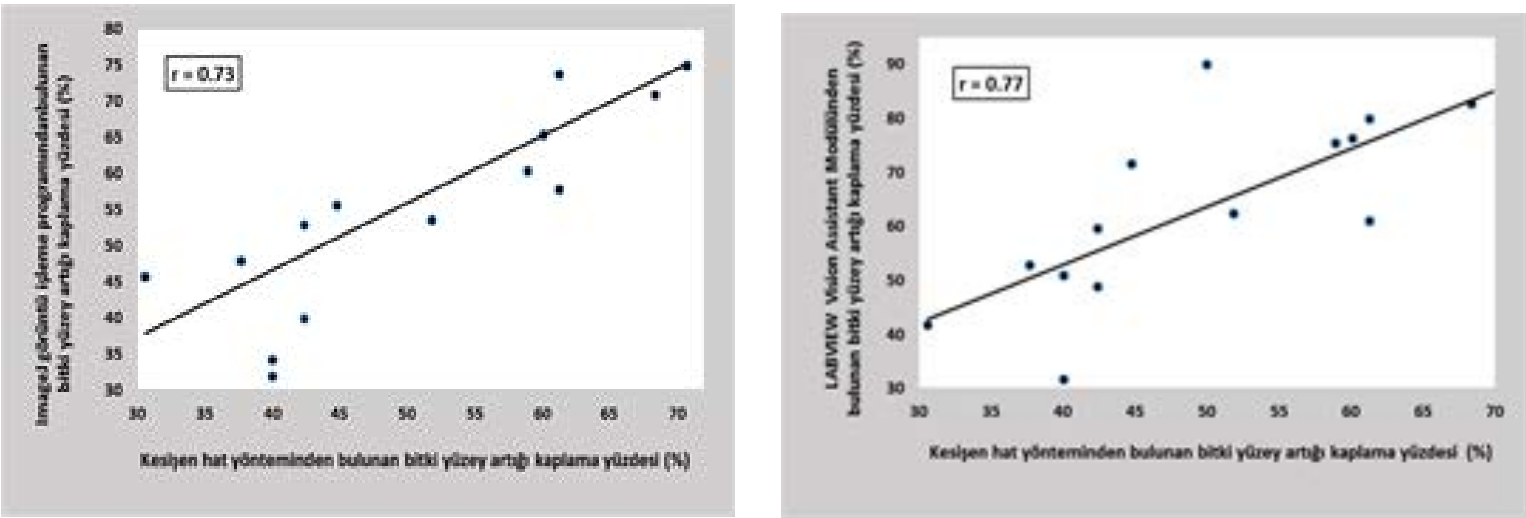

Şekil 7. Kesişen hat yöntemi ile görüntü işleme yöntemleri (ImageJ ve Labview) arasındaki ilişkiler.
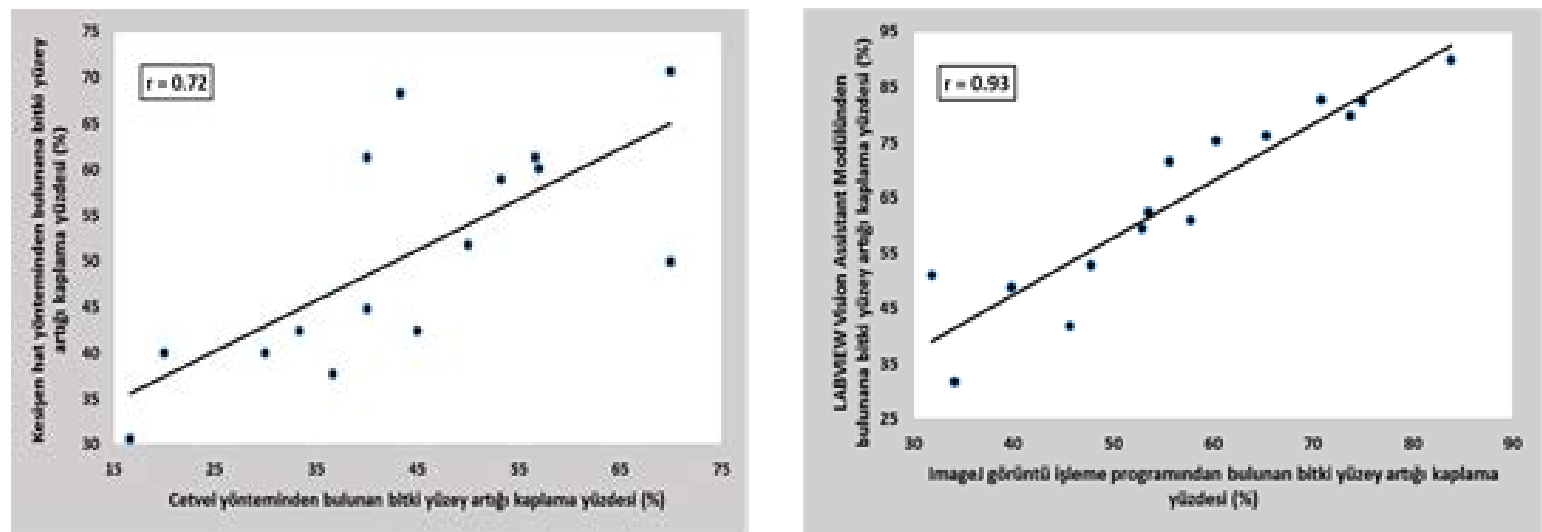

Şekil 8. Cetvel ve kesişen hat yöntemleri ile ImageJ ve Labview yöntemleri arasındaki ilişkiler.

Şekil 6, 7 ve 8 incelendiğinde, korelasyon katsayılarına bağlı olarak yöntemler arasında kuvvetli $(\mathrm{r}=0.72-0.77)$ ve çok kuvvetli $(r=0.93)$ pozitif doğrusal ilişkiler olduğu görülmektedir. Bu sonuç, konuyla ilgili daha önce yapılmış bazı çalışmalardan elde edilen sonuçlarla uyumludur. Morrison ve Chichester (1991); buğday, mısır ve sorgum bitkilerinin yüzey artıklarıyla kaplı tarla koşullarında yapmış oldukları araştırmalarında, video görüntü analizi ve kalibrasyon amaçlı modelden bulunan bitki yüzey artığı kaplama yüzdeleri arasında çok kuvvetli doğrusal ilişki ( $r=0.99$ ) olduğunu belirlemişlerdir. Karabacak (2007); buğday, mısır ve ayçiçeği yüzey 
artıklarıyla kaplı tarlalarda, kesişen hat yöntemi ve Uthscsa Image Tool görüntü işleme programından bulunan bitki yüzey artığı kaplama yüzdeleri arasında buğdayda çok kuvvetli (r=0.91), mısırda kuvvetli $(r=0.70)$, ayçiçeğinde ise orta kuvvetli $(\mathrm{r}=0.67)$ doğrusal ilişkiler bulmuştur. Meyer ve ark. (1988), soya ve mısırın yüzey artıklarıyla kaplı tarla koşullarında 2 farklı görüntü işleme yöntemi ve fotoğraf karşılaştırma yöntemiyle bulunan bitki yüzey artığı kaplama yüzdeleri arasında çok kuvvetli doğrusal ilişkiler belirlemişlerdir. Anonim (2016b), bitki yüzey artığı kaplama yüzdesinin belirlenmesinde referans ölçüm yöntemleri ve görüntü işleme yöntemiyle bulunan sonuçlar arasındaki korelasyon katsayılarının yüksek olduğu, bu nedenle görüntü işleme yönteminden başarıyla yararlanılabileceği açıklanmıştır.

\section{Sonuç}

Buğday yüzey artıklarıyla kaplı bir tarlada 4 farklı yöntem kullanılarak belirlenen ortalama yüzey artığı kaplama yüzdeleri genel olarak değerlendirildiğinde, en düşük değer \% 44.13 ile cetvel yönteminden, en yüksek değer ise \% 64.49 ile Labview Vision Assistant Modülü kullanılarak görüntü işleme yönteminden elde edilmiştir. Duncan testi sonuçlarına göre, kesişen hat yöntemi ve İmageJ görüntü işleme programıyla bulunan bitki yüzey artığı kaplama yüzdeleri arasındaki farklılık istatistiksel olarak önemsiz bulunmuştur. Kesişen hat ve cetvel yöntemlerinin, çok sayıda araştırmacı tarafından bitki yüzey artı̆̆ı kaplama yüzdesinin tahmin edilmesinde referans yöntemler olarak kullanıldığı göz önüne alındığında, İmageJ görüntü işleme programının bitki yüzey artığı kaplama yüzdesinin belirlenmesinde başarıyla kullanılabileceği söylenebilir. Görüntü işleme yöntemiyle bitki yüzey artığ kaplama yüzdesinin hızlı ve güvenilir bir şekilde belirlenmesi; etkin bir yüzey artığ planlamasının yapılmasına, toprak işleme ve ekim yöntemlerinin daha bilinçli seçilmesine, buna bağlı olarak toprak ve su kayıplarının azaltılmasına oldukça önemli katkı sağlayacaktır.

\section{Kaynaklar}

Aase JK, Tanaka DL (1991). Reflectance from four wheat residues cover densities as influenced by three soil backgrounds. Agronomy Journal, 83: 753-757.

Al-Kaisi M, Hanna M (2009). Residue Management \& Cultural Practices. Resources Conservation Practices, PM 1901a, University Extension, Iowa State University, Iowa.

Anonim (2015). Estimating Crop Residue Cover for Soil Erosion Control. Soil Factsheet, Order No: 641.220-1, revised December 2015, Created September 2000, British Columbia, Ministry of Agriculture, Abbotsford, British Columbia.

Anonim (2016). Labview Nedir? http://mekatronikdersi.blogspot.com.tr/2014/10/labview-nedir.html. (Erişim Tarihi: 07 Şubat 2016)

Anonim (2016a). Reduce Need. Agricultural Irrigation Management: Reduce the Need for Irrigation: Maintain Crop Residue, Reduce Tillage. University of Nebraska-Lincoln, UNL Water, http://water.unl.edu/cropswater/reduceneed. (Erişim Tarihi: 08 Nisan 2016).

Anonim (2016b). Crop Residue Estimator. FieldTRAKS Solutions 2016, http://fieldtraks.ca/prod_ cropresidue.html. (Erişim Tarihi: 04 Ağustos 2016).

Bannari A, Pacheco A, Staenz K, McNairn H, Omari K (2006). Estimating and mapping crop residues cover on agricultural lands using hyperspectral and IKONOS data. Remote Sensing of Environ., 104: 447-459.

Corak SJ, Kaspar TC, Meek DW (1993). Evaluating methods for measuring residue cover. Journal of Soil and Water Conservation, 48 (1): 70-74.

Daughtry CST, McMurtey III JE, Kim MS, Chappelle EW (1997). Estimating crop residue cover by blue fluorescence imaging. Remote Sensing of Environment, 60: 14-21.

Daughtry CST (2001). Estimating Crop Residue Cover by Remote Sensing. Hydrology and Remote Sensing Lab. USDA-BARC-ARS.

Daughtry CST, Doraiswamy PC, Hunt Jr ER, Stern AJ, McMurtrey III JE, Prueger JH (2006). Remote sensing of crop residue cover and soil tillage intensity. Soil \& Tillage Research, 91 (2006): 101-108.

Dickey EC., Harlan, PW, Vokal D (1981). Crop residue management for water erosion control. University of Nebraska-Lincoln, DigitalCommons @ University of Nebraska-Lincoln, Biological Systems Engineering: Papers and Publications, G18-544, 4-1-1981, Nebraska.

Dickey EC, Havlin J (1985). Estimating Crop Residue Using Residue to Help Control Wind and Water Erosion. University of Nebraska-Lincoln, Biological Systems Engineering, Lincoln, NE Leaft No: 3, 1-1-1985, Nebraska.

Dickey EC, Shelton DP, Jasa PJ (1986). Residue Management for Soil Erosion Control. University of NebraskaLincoln, Lincoln Extension, G18-544, 1-1-1981, Nebraska.

Dursun Göknur İ (2002). Bitki yüzey artığı kaplama oranının belirlenmesinde kullanılan yöntemler. Türk-Koop Ekin Dergisi, Y1l: 6, Say1: 21, s. 60-65, Ankara. 
Dursun İ (2015). Toprak İşleme Alet ve Makinaları. Ankara Üniversitesi Basımevi, Ankara Üniversitesi Ziraat Fakültesi, Yayın No: 1618, Ders Kitabı: 570, 584 s., Ankara.

Hickman JS, Schoenberger DL (1989). Estimating Wheat Residue. Cooperative Extension Service, L-783, Crops and Soils 4-5 (Soil Conservation), Manhattan, Kansas.

Karabacak H (2007). Bitki Yüzey Artığı Kaplama Oranının Görüntü İşleme Tekniğiyle Belirlenmesi. Ankara Üniversitesi, Fen Bilimleri Enstitüsü, Tarım Makinaları Anabilim Dalı, Yayımlanmamış Yüksek Lisans Tezi, 66 s., Ankara.

Kocabaş Z, Özkan MM, Başpınar E (2013). Temel Biyometri. Ankara Üniversitesi Basımevi, Ankara Üniversitesi Ziraat Fakültesi, Yayın No: 1606, Ders Kitabı: 558, 381s., Ankara.

Laflen JM, Amemiya M, Hintz EA (1981). Measuring crop residue cover. Soil and Water Conservation Society, Journal of Soil and Water Conservation, 36 (6): 341-343.

McMurtrey III JE, Chappelle EW, Daughtry CST, Kirn MS (1993). Fluorescence and reflectance of crop residue and soil. ]. Soil Water Conserv. 48: 207-213.

Meyer GE, Stepanek A, Shelton DP, Dickey EC (1988). Electronic image analysis of crop residue cover on soil. Transactions of ASAE, 31 (2): 968-973.

Morrison JE, Chichester FW (1991). Still video image analysis of crop residue soil covers. Transactions of the ASAE, 34 (6): 2469-2474.

Presley D (2013). Estimating Crop Residue Cover. K-State Agronomy eUpdates, Sayı: 426, K-State Research and Extension, Manhatan.

Rice CW (2002). Storing Carbon in Soil: Why and how? Geotimes (2002), pp. 1-5.

Shelton D, Jasa PJ (1995). Estimating Percent Residue Cover Using the Photo-Comparison Method. G95-1134, 1-1-1995, Field Crops, H-3, Conservation and Management, University of Nebraska, Nebraska.

Shelton D, Jasa PJ (2009). Estimating Percent Residue Cover Using the Line-Transect Method. G1931, Nebraska Extension, NebGuide, Conservation and Management, University of Nebraska, Nebraska.

Shelton D, Smith JA, Jasa PJ, Kanable R (1995). Estimating Percent Residue Cover Using the Calculation Method. G05-1135-A, Field Crops, H-4, Conservation and Management, University of Nebraska, Nebraska.

Streck NA, Rundquist D, Connot J (2002). Estimating residual wheat dry matter from remote sensing measurements. Photogrammetric Engineering \& Remote Sensing, 68 (11): 1193-1201.

Wysocki D (1988). Measuring Residue Cover. PNW Conservation Tillage Handbook Series, Chapter 3-Residue Management, No: 9.

Zheng B, Campbell JB, Serbin G, Galbraith JM (2014). Remote sensing of crop residue and tillage practices: Present capabilities and future prospects. Soil \& Tillage Research, 138: 26-34 